This is an unedited manuscript published in the Journal of Vocational Behavior

Please note that the published version underwent minor additional editing in style and content.

Complete reference:

Hirschi, A., \& Valero, D. (2015). Career adaptability profiles and their relationship to adaptivity and adapting. Journal of

Vocational Behavior, 88, 220-229. doi: 10.1016/j.jvb.2015.03.010

\title{
Career Adaptability Profiles and Their Relationship to Adaptivity and Adapting
}

\author{
Andreas Hirschi* and Domingo Valero ${ }^{a}$ \\ University of Bern, Switzerland
}

\author{
*Corresponding author: University of Bern, Institute of Psychology, Fabrikstrasse 8, CH-3012 Bern, Switzerland; \\ Tel. +41 3163186 07; Fax +41 3163182 12; e-mail: andreas.hirschi@psy.unibe.ch \\ aUniversity of Bern, Institute of Psychology, Fabrikstrasse 8, CH-3012 Bern, Switzerland; \\ Tel.+41 3163134 17; Fax +4131631 82 12; e-mail: domingo.valero@psy.unibe.ch
}

Acknowledgement. This research was supported by an individual research grant awarded to Andreas Hirschi by the Deutsche Forschungsgemeinschaft 332 (DFG), GZ: HI 1530/2-1. The funding source had no involvement in study design, in the collection, analysis and interpretation of data, in the writing of the report, or in the decision to submit the article for publication.

\begin{abstract}
Research on career adaptability predominantly uses variable-centered approaches that focus on the average effects in terms of the predictors and outcomes within a given sample. Extending this research, the present paper used a person-centered approach to determine whether subgroups with distinct adaptability profiles in terms of concern, control, curiosity and confidence can be identified. We also explored the relationship between the various adaptability profiles and adapting (career planning, career decision-making difficulties, career exploration, and occupational self-efficacy beliefs) and adaptivity (core self-evaluations and proactivity). Using latent profile analysis, we found distinct adaptability profiles among 350 German university students. Students with different profiles differed significantly in their levels of adapting. This finding was confirmed in a second study of 1,226 students selected from the same population. In both samples, the adaptability profiles differed mainly in terms of their adaptability levels but not their shape. Moreover, in both samples, the students whose profiles indicated generally higher adaptability showed more adapting compared with the students whose profiles indicated generally lower adaptability. Study 2 also showed that students with higher-adaptability profiles showed significantly higher adaptivity. The results suggest that level effects dominate adaptability profiles, implying the existence of a general adaptability factor within university students that is meaningfully related to adapting and adaptivity.
\end{abstract}

Keywords: career adaptabilities; latent profile analysis; adapting; adaptivity 


\section{Introduction}

Vocational psychology has a long-standing interest in exploring the personal characteristics that allow people to successfully manage their careers and integrate their self-concept into their working role. Emerging from the earlier concepts of career maturity (Savickas, 1984; Super, 1955), the concept of career adaptability (Savickas, 1997; Super \& Knasel, 1981) has gained increased attention as a critical construct in this regard. In its most recent conceptualization, career adaptability refers to "a psychosocial construct that denotes an individual's resources for coping with current and anticipated tasks, transitions, traumas in their occupational roles" (Savickas \& Porfeli, 2012, p. 662). Empirical studies across cultures have confirmed that individuals with higher career adaptability show higher career satisfaction (Zacher, 2014), less work stress (Johnston, Luciano, Maggiori, Ruch, \& Rossier, 2013), and higher personenvironment fit perception (Guan et al., 2013), among other positive outcomes.

Career adaptability is a multidimensional construct that, according to Savickas' (2013) model, consists of four aspects: concern, control, curiosity, and confidence. In the existing research, studies have used a variable-centered approach to explore the relationship between career adaptability dimensions and a range of antecedents, correlates, and outcomes. A variable-centered approach allows an examination of the extent to which each adaptability dimension is related on average to other variables within a given sample. However, this approach does not take into account that within a population, several distinct subpopulations might exist that show different profiles of career adaptability. Moreover, exploring such subgroups can provide insights into the extent to which different adaptability profiles are related to antecedent and outcome variables (Vondracek \& Porfeli, 2002).

The aim of the present paper is to explore career adaptability from a person-centered approach. First, we used a latent profile analysis to examine whether different subgroups with distinct adaptability profiles could be identified; we established the existence of different adaptability profiles in a German university student sample (Study 1); and we confirmed these profiles in a second sample from the same population (Study 2). This examination allowed us to establish how different subgroups show different combinations of the four adaptability resources. Second, we investigated how different adaptability profiles were related to adapting outcomes in terms of career planning, career decision-making difficulties, career exploration, and occupational selfefficacy beliefs. We again provided support for these relationships in Study 1 and then replicated the results in Study 2. These results showed the extent to which individuals with different combinations of the four adaptability resources differ in the adaptive behaviors and attitudes that are instrumental for addressing changing conditions and tasks in working life. Finally, in Study 2 we explored the extent to which different adaptability profiles were related to adaptivity antecedents in terms of core selfevaluations (CSE) and a proactive personality. In doing so, we provided insight into how individuals with different adaptability profiles differed in their basic adaptive readiness and the extent to which the different adaptability profiles could be explained by differences in adaptivity.

\section{Career Adaptability as a Multidimensional Construct}

Career adaptability can be empirically represented as a higher-order latent factor that is indicated by its more specific subdimensions of concern, control, curiosity, and confidence (Savickas \& Porfeli, 2012). This factor has been found across different language versions of the Career AdaptAbilities Scale (CAAS; Savickas \& Porfeli, 2012), which is the most prominent measure of career adaptability. These findings suggest that the four adaptability dimensions share significant variance. However, from a conceptual standpoint, career adaptability should be seen as a formative, aggregate construct, and each 
of its subdimensions contributes to the overall level of adaptability alone and in combination (Savickas, 2013). The empirical validity of the notion that concern, control, curiosity, and confidence are not interchangeable representations of career adaptability stems from studies that show that different dimensions of career adaptability can be differentially related to potential predictors and outcomes (Guan et al., 2013; Hirschi, Herrmann, \& Keller, 2015; Porfeli \& Savickas, 2012; Rossier, Zecca, Stauffer, Maggiori, \& Dauwalder, 2012).

The theoretical and empirical notion that the four career adaptability dimensions are not just redundant representations of the higher-order career adaptability construct implies that individuals with different adaptability profiles as indicated by concern, control, curiosity, and confidence might exist. This paper contributes to the career adaptability research literature by applying a personcentered approach to detecting such differing adaptability profiles.

\section{A Person-Centered Approach to Investigating Career Adaptability}

The variable-centered approaches used in existing studies of career adaptability examine the unique and independent relationships of the four adaptability dimensions (and/or their sum score) with antecedents, correlates, and outcomes. Consequently, these studies provide information about how these constructs are related on average within a given sample. However, such an approach ignores the possibility that within a given population, several subpopulations might exist that show different combinations of the four adaptability dimensions. Such a person-centered approach seems particularly appropriate in light of the increasing individualization of career development (Vondracek \& Porfeli, 2002) and the person-focused approach used in career counseling, in which career adaptability can play a major role (Savickas, 2013; van Vianen, De Pater, \& Preenen, 2009).
Career adaptability profiles can differ quantitatively and qualitatively. Quantitative profile differences refer to the absolute level of the profile indicators (i.e., the adaptability dimensions) across groups of individuals. Conversely, qualitative differences refer to the shape of the profile or the relative level of the indicators within a group (Wang \& Hanges, 2011). The identification of subgroups of individuals with distinct combinations of the four adaptability dimensions could enhance our understanding of the career adaptability construct and its relationship with predictors and outcomes because several important questions can be addressed using a person-centered approach: For example, what types of subgroups with distinct combinations of career adaptability profiles can be identified in a given population? What is the prevalence of these different profiles? How are these profiles related to the antecedents and outcomes of career adaptability?

\section{Study 1: Establishing Career Adaptability Profiles}

The first goal of this study was to apply a personcentered approach to career adaptability and explore whether individuals with distinct career adaptability profiles can be identified. Hence, this study was guided by the following general research question: Research Question 1: Are there quantitatively and qualitatively distinct profiles of career adaptability?

A second goal of this study was to explore the relationships between different adaptability profiles and the theoretical outcomes of adaptability. An important outcome that could be related to different adaptability profiles is adapting. Adapting, or adapting responses, refers to performing adaptive behaviors and possessing adaptive attitudes that help when addressing changing career conditions and dealing with career development tasks (Savickas, 2013). Adapting should be considered an outcome of career adaptability; it is increased when an individual possesses career adaptability resources in terms of concern, control, curiosity, and confidence (Hirschi et al., 2015). In our studies, we were specifically 
interested in exploring the extent to which individuals with different career adaptability profiles might differ in their adapting responses. Such an investigation could extend previous variable-centered research that showed that adaptability is on average positively related to different indictors of adapting, such as career exploration and career decision-making (Hirschi et al., 2015; Urbanaviciute, Kairys, Pociute, \& Liniauskaite, 2014). By applying a person-centered approach, we can go beyond these findings and explore the extent to which such relationships exist for groups of individuals with different adaptability profiles. In our study, we specifically examined adapting in terms of the dimensions proposed by Hirschi et al. (2015): career planning, career decisionmaking difficulties, career exploration, and occupational self-efficacy beliefs. Thus, we considered the second research question:

Research Question 2: Do career adaptability profiles show different levels of adapting in terms of (a) career planning; (b) career decision-making difficulties; (c) career exploration; and (d) occupational self-efficacy beliefs?

\section{Method Study 1}

Participants and procedure. After obtaining addresses from the university registration office for students enrolled in the second and third year at a German university $(\mathrm{N}=1,773)$, we contacted the students via email asking them to participate in our online survey. After two reminder emails, each sent one week apart, we reached a final response rate of $20 \%(\mathrm{~N}=360)$. The participants could take part in a lottery drawing with several prizes that totaled US\$ 1,000 in value. Because outliers can significantly bias the results in multivariate data analyses (Tabachnik \& Fidell, 2013), we checked for multivariate outliers using the Mahalanobis distance based on the scores on the four adaptability subscales and applying a $\mathrm{p}<$ .001 level. Ten cases were identified as outliers and excluded from the data analyses. The final sample (N $=350$ ) was $69 \%$ female, with a mean age of 24.33 (SD $=3.29$ ) years. The participants studied a wide range of different majors. The largest groups were business administration and management (29\%), cultural studies and political sciences (18\%), teacher training (16\%), psychology and business psychology (13\%), and environmental sciences (8\%).

Measures. If not stated otherwise, the measures applied a five-point Likert scale from 1 (strongly disagree) to 5 (strongly agree). Cronbach's alpha, the means and standard deviations, and the correlations between variables are reported in Table 1.

Career adaptability. We used the German Career Adapt-Abilities Scale (CAAS international form 2.0) (Johnston et al., 2013; Savickas \& Porfeli, 2012) to assess the four dimensions of career adaptability. This scale consists of 24 items. Six items assess each of the four subscales: concern (e.g., "concerned about my career"), control (e.g., "making decisions by myself"), curiosity (e.g., "becoming curious about new opportunities"), and confidence (e.g., "performing tasks efficiently"). The participants responded on a five-point scale ranging from 1 (I don't have the ability to...) to 5 (I have a very strong ability to...). Johnston and colleagues (2013) found good Cronbach's alphas for the four subscales ranging from .86 to .88 and confirmed the four-factor structure. Higher CAAS scale scores were related to lower work stress and more positive orientations to happiness (Johnston et al., 2013).

Adapting. Career planning was assessed with the career planning scale developed by Gould (1979). This scale consists of six items (e.g., "I have a strategy for reaching my career goals"). The German version by Abele and Wiese (2008) showed positive relationships with objective and subjective career success in a sample of German professionals.

Career decision-making difficulties were assessed with the German-language version of the Vocational Identity Scale (Holland, Daiger, \& Power, 1980; Jörin, Stoll, Bergmann, \& Eder, 2003). The scale consists of seven items (e.g., "I'm not sure yet which occupations I could perform successfully") and was significantly related to other measures of career decidedness, 
Table 1

Means, Standard Deviations, Cronbach's Alpha Values, and Intercorrelations of the Variables in Study 1 and Study 2

\begin{tabular}{|c|c|c|c|c|c|c|c|c|c|c|c|c|c|}
\hline & & $M$ & $S D$ & $\alpha$ & 1 & 2 & 3 & 4 & 5 & 6 & 7 & 8 & 9 \\
\hline \multirow[t]{2}{*}{1} & Concern & 3.67 & .57 & .80 & - & $.31^{* * *}$ & $.30^{* * *}$ & $.40^{* * *}$ & $.55^{* * *}$ & $-.40 * * *$ & $.38^{* * *}$ & $.36^{* * *}$ & - \\
\hline & & 3.64 & .62 & .83 & & & & & & & & & \\
\hline \multirow[t]{2}{*}{2} & Control & 3.91 & .65 & .82 & & - & $.44^{* * *}$ & $.55^{* * *}$ & $.27^{* * *}$ & $-.31^{* * *}$ & $.11^{*}$ & $.50 * * *$ & - \\
\hline & & 3.94 & .64 & .82 & $.39^{* * *}$ & & & & & & & & \\
\hline \multirow[t]{2}{*}{3} & Curiosity & 3.81 & .59 & .80 & & & - & $.50^{* * *}$ & .07 & -.07 & $.17^{* *}$ & $.32^{* * *}$ & - \\
\hline & & 3.68 & .62 & .79 & $.41^{* * *}$ & $.48^{* * *}$ & & & & & & & \\
\hline \multirow[t]{2}{*}{4} & Confidence & 4.02 & .51 & .79 & & & & - & $.21^{* * *}$ & $-.21^{* * *}$ & $.23^{* * *}$ & $.47^{* * *}$ & - \\
\hline & & 3.99 & .55 & .82 & $.48^{* * *}$ & $.59 * * *$ & $.48^{* * *}$ & & & & & & \\
\hline \multirow[t]{2}{*}{5} & Career planning & 3.35 & .83 & .87 & & & & & - & $-.70 * * *$ & $.20 * * *$ & $.37^{* * *}$ & - \\
\hline & & 3.30 & .89 & .87 & $.54^{* * *}$ & $.25^{* * *}$ & $.11^{* * *}$ & $.23^{* * *}$ & & & & & \\
\hline \multirow[t]{2}{*}{6} & Career decision- & 2.38 & .86 & .89 & & & & & & - & -.07 & $-.38 * * *$ & - \\
\hline & making difficulties & 2.46 & .91 & .88 & $-.45^{* * *}$ & $-.38^{* * *}$ & $-.20 * * *$ & $-.31^{* * *}$ & $-.73^{* * *}$ & & & & \\
\hline \multirow[t]{2}{*}{7} & Career exploration & 3.24 & .82 & .90 & & & & & & & - & $.17^{* *}$ & - \\
\hline & & 3.05 & .83 & .89 & $.42^{* * *}$ & $.15^{* * *}$ & $.25^{* * *}$ & $.21^{* * *}$ & $.25^{* * *}$ & $-.18^{* * *}$ & & & \\
\hline \multirow[t]{2}{*}{8} & Occupational self- & 4.31 & .68 & .82 & & & & & & & & - & - \\
\hline & efficacy & 4.26 & .70 & .82 & $.43^{* * *}$ & $.54^{* * *}$ & $.41^{* * *}$ & $.50^{* * *}$ & $.37^{* * *}$ & $-.45^{* * *}$ & $.23^{* * *}$ & & \\
\hline \multirow[t]{2}{*}{9} & Core self-evaluations & - & - & - & & & & & & & & & - \\
\hline & & 3.73 & .56 & .84 & $.34^{* * *}$ & $.62^{* * *}$ & $.29^{* * *}$ & $-.48^{* * *}$ & $.32^{* * *}$ & $-.47^{* * *}$ & $.10^{* * *}$ & $.57^{* * *}$ & \\
\hline \multirow[t]{2}{*}{10} & Proactivity & - & - & - & & & & & & & & & \\
\hline & & 3.58 & .56 & .79 & $.48^{* * *}$ & $.47^{* * *}$ & $.46^{* * *}$ & $.55^{* * *}$ & $.29 * * *$ & $-.32 * * *$ & $.33^{* * *}$ & $.51^{* * *}$ & $.41^{* * *}$ \\
\hline
\end{tabular}

Note. The upper values for means, standard deviations, and Cronbach's alpha are from Study 1 with $N=350$. Lower italicized values are from Study 2 with $N=1,226$. Correlations from Study 1 are reported above the diagonal. Correlations from Study 2 are reported below the diagonal and italicized. $* p<.05,{ }^{* *} p<.01,{ }^{* * *} p<.001$ 
career planning, and career exploration in adolescent and college student samples (Hirschi \& Herrmann, 2013).

Career exploration was assessed using the Career Exploration Scale developed in German by Hirschi (2009). Four items assess aspects of self-exploration behaviors (e.g., "reflection about personal interests"), and six items assess environmental exploration (e.g., "gathering information about interesting career paths"). A previous study found that the scale score correlated positively with other measures of career exploration, career decidedness, career planning, and career choice congruence (Hirschi, 2009).

Occupational self-efficacy was assessed with the short version of the German-language occupational self-efficacy scale developed by Rigotti, Schyns, and Mohr (2008). It consists of six items (e.g., "Whatever comes my way in my job, I can usually handle it") answered on a six-point scale ranging from 1 (not at all true) to 6 (completely true). The scale's authors (Rigotti et al., 2008) described significant relationships between the scale scores and job satisfaction, commitment, job performance, and job insecurity.

\section{Results and Discussion Study 1}

Confirmatory factor analysis for CAAS items. All of the analyses were performed with MPlus 7.3 (Muthén \& Muthén, 2012). First, we performed a confirmatory factor analysis with the 24 CAAS items loading onto the four intercorrelated factors (concern, control, curiosity, and confidence) to confirm the factor structure of the CAAS. Model fit was assessed using the indices recommended by $\mathrm{Hu}$ and Bentler (1999): the comparative fit index (CFI), the Tucker-Lewis index (TLI), the root mean squared error of approximation (RMSEA), and the standardized root mean squared residual (SRMR). Values below .08 for the RMSEA and SRMR complemented by a CFI and TLI close to .95 or above indicate a good model fit. We obtained a moderately acceptable model fit for the proposed four-factor model of the CAAS measure $(\chi 2=504.60, d f=246$, $p<.001, \quad$ CFI $=.89, \quad$ TLI $=.88, \quad$ RMSEA $=.06$, SRMR = .06). This is in line with previous results using this scale (Johnston et al., 2013). The intercorrelations among the four adaptability factors were small but significant (all $\mathrm{r}<.21, p<.001$ ). An examination of the modification indices revealed several highly correlated error terms for certain items within a scale. In a stepwise process that released the most highly correlated error term each time, we freed two error terms until an acceptable model fit was reached $(\alpha 2=443.98, d f=244, p<.001$, CFI $=.91$, TLI $=.90$, RMSEA $=.05$, SRMR $=.06$ ).

Latent profile analysis. To address Research Question 1, we performed a latent profile analysis (LPA) using the four adaptability subscale scores as latent profile indicators. We used a stepwise procedure to determine the number of latent profiles, starting with a solution of two profiles and in each step examining (a) the sample-adjusted Bayesian information criterion (SABIC), (b) the bootstrapped likelihood-ratio test and its significance level (BLRT), (c) the posterior classification probabilities of each profile, and (d) the number of cases in each profile. LPA fit statistics do not offer clear cutoff values. The best model should have lower SABIC values compared with the other profile solutions, the BLRT should be significant at $\mathrm{p}<.05$, none of the profiles should be small, and posterior classification probabilities should show clearly defined profiles. Finally, the selected model should make sense theoretically (Marsh et al., 2009).

After investigating the fit statistics for solutions with two to six profiles, we chose the five-profile solution because it showed the lowest SABIC value (2143.95) and the last significant BLRT value (25.96, $\mathrm{p}<.05$ ) before the results became nonsignificant when six profiles were considered (SABIC: 2148.87; BLRT: 8.50, ns.). The posterior classification probabilities indicated that each of the five profiles could adequately predict a participant's profile membership, and there was no profile with an unacceptably low size (Table 2). The means of the 
Table 2

Means of Adaptability Subscales, Overall Adaptability, Antecedents, and Outcomes for Study 1 and Study 2

\begin{tabular}{lccccccc}
\hline Profile & $n$ & Concern & Control & Curiosity & Confidence & CSE & Proactivity \\
\hline Low & 19 & 3.12 & 2.64 & 3.00 & 3.00 & - & - \\
Below average & 65 & 3.34 & 3.55 & 3.60 & 3.49 & - & - \\
Average & 181 & 3.67 & 4.04 & 3.84 & 4.05 & - & - \\
Helpless- & & & & & & & \\
passive & 12 & 3.80 & 3.27 & 2.70 & 3.90 & - & - \\
High & 73 & 4.04 & 4.37 & 4.32 & 4.68 & - & - \\
\hline & & & & Study 2 & & & \\
\hline Very low & 12 & 2.44 & 2.52 & 2.49 & 2.42 & 2.86 & 2.55 \\
Low & 121 & 3.00 & 3.17 & 3.06 & 3.17 & 3.16 & 2.98 \\
Below average & 352 & 3.43 & 3.60 & 3.45 & 3.79 & 3.55 & 3.29 \\
High & 190 & 4.18 & 4.62 & 4.35 & 4.71 & 3.99 & 3.75 \\
Above average & 551 & 3.77 & 4.15 & 3.77 & 4.10 & 4.23 & 4.21 \\
\hline
\end{tabular}

Note. The means for the distal outcomes can be retrieved from Table 5 for Study 1 and Table 7 for Study 2.

For Study 1 no core self-evaluations and proactivity values are available. CAAS = Career adaptabtility scale. CSE $=$ Core self-evaluations. 


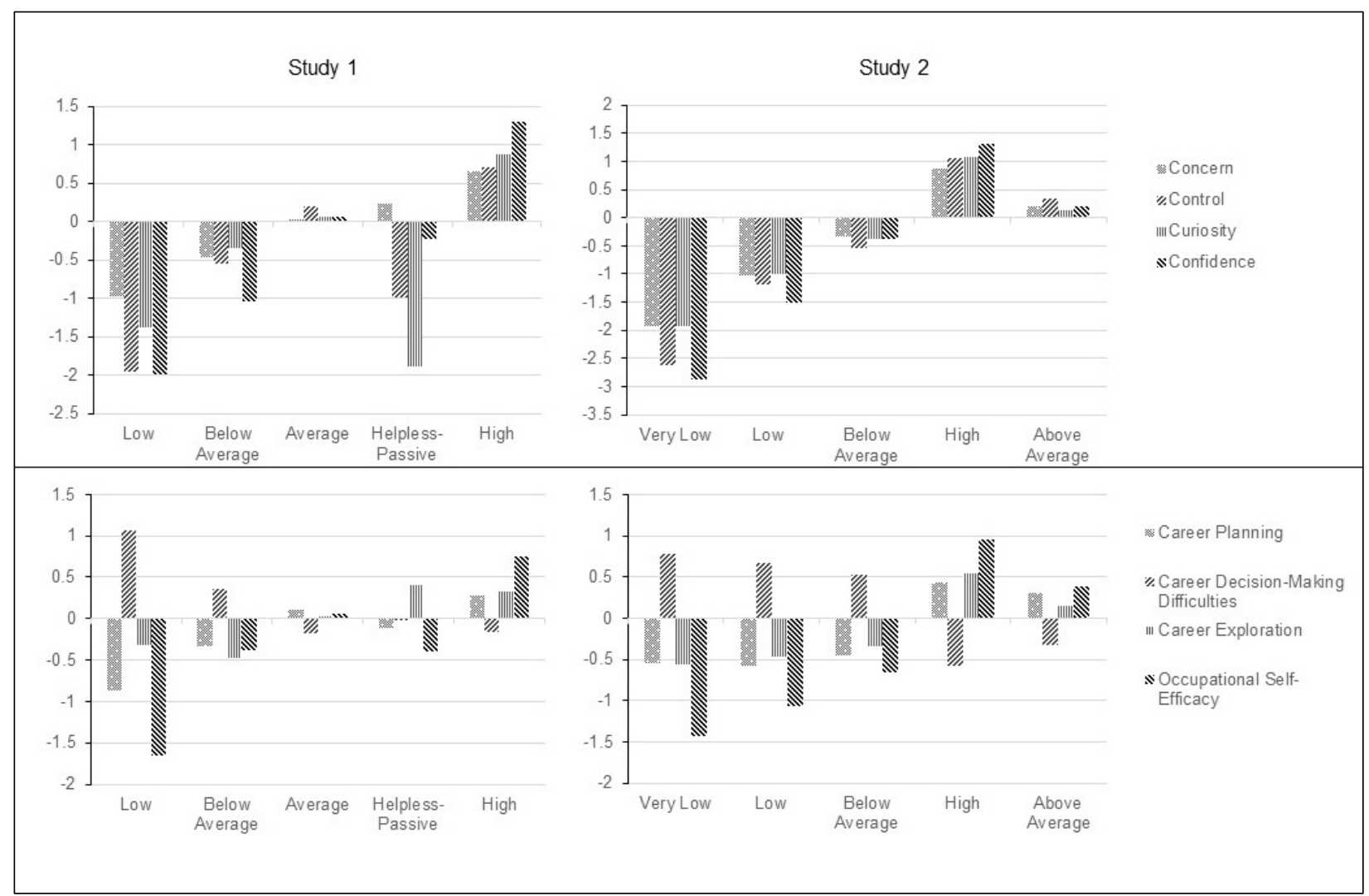

Figure 1. Top left diagram represents the standardized means of latent profiles in Study 1. Bottom left diagram represents the standardized means of adapting variables by latent adaptability profile in Study 1. Right diagrams represent the standardized means of latent profiles and adapting variables by latent profile in Study 2 respectively.

subscales concern, control, curiosity, and confidence for the five profiles can be retrieved from Table 2 . Figure 1 shows the five latent profiles' standardized means in the four adaptability subscales. The first profile, with $5 \%$ of the cases, was characterized by considerably below-average adaptability scores on all four subscales; we labeled this profile low adaptability. The second profile (19\%) was characterized by below-average values for all four adaptability subscales, and we labeled this profile below-average adaptability. The third profile (52\%) was characterized by values near the standardized mean for all four adaptability subscales, and we labeled this profile average adaptability. The fourth profile (3\%) was characterized by mean levels of concern and confidence, but low levels of control and curiosity. We labeled this profile helpless-passive.
The fifth profile (21\%) was characterized by the highest values for all four adaptability subscales, and we labeled this profile high adaptability. Overall, four of the five profiles were quantitatively different, indicating low to high scores on all four adaptability subscales. The fourth profile, helpless-passive, was the only one that differed qualitatively from the rest. Regarding our Research Question 1, we could therefore confirm the existence of quantitatively different adaptability profiles but did not find clear support for qualitatively different profiles.

To address Research Question 2, we modeled the four adapting measures as auxiliary variables of the five latent adaptability profiles using the $\mathrm{BCH}$ command in MPlus. This command reports mean levels across profiles for each auxiliary variable and compares overall and between-profile means using 
Table 3

Comparison of Adapting Distal Outcomes Study 1 and Study 2

\begin{tabular}{|c|c|c|c|c|c|c|c|c|c|c|c|c|}
\hline & \multicolumn{6}{|c|}{ Profiles Study 1} & \multicolumn{6}{|c|}{ Profiles Study 2} \\
\hline & Low & $\begin{array}{c}\text { Below } \\
\text { average }\end{array}$ & Average & $\begin{array}{l}\text { Helpless } \\
\text {-passive }\end{array}$ & High & $\begin{array}{l}\text { Overall } \\
\text { test }\end{array}$ & $\begin{array}{l}\text { Very } \\
\text { low }\end{array}$ & Low & $\begin{array}{c}\text { Below } \\
\text { average }\end{array}$ & High & $\begin{array}{c}\text { Above } \\
\text { average }\end{array}$ & $\begin{array}{l}\text { Overall } \\
\text { test }\end{array}$ \\
\hline $\begin{array}{l}\text { Career } \\
\text { planning (A) }\end{array}$ & $\begin{array}{l}2.64 \mathrm{C}, \mathrm{D}, \\
\mathrm{E}\end{array}$ & $3.08 \mathrm{C}, \mathrm{E}$ & $3.44 \mathrm{~A}, \mathrm{~B}$ & $3.26 \mathrm{~A}$ & $\begin{array}{l}3.59_{\mathrm{A}} \\
\text { B }\end{array}$ & $26.55^{* * *}$ & $2.81 \mathrm{D}, \mathrm{E}$ & $2.78 \mathrm{D}, \mathrm{E}$ & $2.90 \mathrm{D}, \mathrm{E}$ & $\begin{array}{l}3.68_{\mathrm{A}, \mathrm{B}} \\
\mathrm{C}\end{array}$ & $3.57_{\mathrm{A}, \mathrm{B}, \mathrm{C}}$ & $149.08^{* * *}$ \\
\hline CDMD (B) & $\begin{array}{l}3.31_{B, C} \\
D, E\end{array}$ & $2.69_{\mathrm{A}, \mathrm{C}, \mathrm{E}}$ & $2.22_{\mathrm{A}, \mathrm{B}}$ & $2.36_{\mathrm{A}}$ & $\begin{array}{l}2.24_{\mathrm{A}} \\
\text { B }\end{array}$ & $29.40^{* * *}$ & $3.18_{\mathrm{D}, \mathrm{E}}$ & $3.08_{\mathrm{D}, \mathrm{E}}$ & $2.94_{D, E}$ & $\begin{array}{l}1.94_{\mathrm{A}, \mathrm{B}} \\
\mathrm{C,E}\end{array}$ & $2.17_{\mathrm{A}, \mathrm{B}, \mathrm{C}, \mathrm{E}}$ & $217.68^{* * *}$ \\
\hline $\begin{array}{l}\text { Career } \\
\text { exploration (C) }\end{array}$ & $2.98 \mathrm{E}$ & $2.84_{\mathrm{C}, \mathrm{D}, \mathrm{E}}$ & $3.26_{\mathrm{B}}$ & $3.57_{\text {в }}$ & $\begin{array}{l}3.51_{\mathrm{A}} \\
\text { B }\end{array}$ & $21.67^{* * *}$ & $2.58 \mathrm{D}, \mathrm{E}$ & $2.66_{\mathrm{D}, \mathrm{E}}$ & $2.77_{D, E}$ & $\begin{array}{l}3.50_{\mathrm{A}, \mathrm{B}} \\
\mathrm{C}, \mathrm{E}\end{array}$ & $3.17_{\mathrm{A}, \mathrm{B}, \mathrm{C}, \mathrm{D}}$ & $111.39^{* * *}$ \\
\hline $\begin{array}{l}\text { Occupational } \\
\text { self-efficacy (D) }\end{array}$ & $\begin{array}{l}3.19_{\mathrm{B}, \mathrm{C}} \\
\mathrm{D}, \mathrm{E}\end{array}$ & $4.05_{\mathrm{A}, \mathrm{C}, \mathrm{E}}$ & $4.35 \mathrm{~A}, \mathrm{~B}, \mathrm{E}$ & $4.04 \mathrm{~A}, \mathrm{E}$ & $\begin{array}{l}4.82_{\mathrm{A}} \\
\mathrm{B}, \mathrm{C}, \mathrm{D}\end{array}$ & $109.73^{* * *}$ & $\begin{array}{l}3.26 \mathrm{C}, \mathrm{D}, \\
\mathrm{E}\end{array}$ & $\begin{array}{l}3.51_{C, D}, \\
E\end{array}$ & $3.80_{\mathrm{A}, \mathrm{B}, \mathrm{D}, \mathrm{E}}$ & $\begin{array}{l}4.93_{\mathrm{A}, \mathrm{B}} \\
\mathrm{C,E}\end{array}$ & $4.53_{\mathrm{A}, \mathrm{B}, \mathrm{C}, \mathrm{D}}$ & $536.79^{* * *}$ \\
\hline
\end{tabular}

Note. $N=350$ in Study 1, $N=1226$ in Study 2. Analyses were performed with the BCH procedure in MPlus 7.3. CDMD = Career decision-making difficulties. The values for career planning, career decision-making difficulties, career exploration, and occupational self-efficacy for each profile are means. The overall significance test values are Chi-square values with $d f=4$. Subscripts designate profiles which differ significantly at $p<.05$.

$* * * p<.001$ 
Wald tests. The $\mathrm{BCH}$ procedure was chosen because it was the most robust option (for a discussion of the procedure see Bakk \& Vermunt, in press).

The results (Table 3 and Figure 1) indicated significant differences in adapting among the five profiles. These differences largely corresponded to the increased levels of adaptability across the five profiles: The profiles with higher adaptability across the four dimensions also tended to show higher levels of career planning, career exploration, and occupational self-efficacy and lower levels of career decision-making difficulties. The helpless-passive profile showed a qualitatively different pattern compared with the four other profiles. It showed intermediate values for career planning and career decision-making difficulties, but a relatively high value for career exploration and a below average score for occupational self-efficacy. Regarding Research Question 2, this implies that that the different adaptability profiles also differ in terms of their adapting values.

Study 2: Replicating and Extending Career Adaptability Profiles

The first purpose of Study 2 was to replicate the observed career adaptability profiles in Study 1 using a different and larger sample from the same population. Such replications are recommended to prove the validity and generalizability of latent profiles (Wang \& Hanges, 2011). We proposed that most individuals would again be grouped into a number of profiles showing homogeneously low, average, or high levels for all four adaptability subscales:

Hypothesis 1: A series of quantitatively different career adaptability profiles can be identified.

Second, we aimed to replicate with a new sample the differences in adapting among the adaptability profiles found in Study 1. We assumed that we could replicate these findings and proposed.

Hypothesis 2: Individuals with lower-adaptability profiles will show (a) less career planning, (b) more career decision-making difficulties, (c) less career exploration, and (d) lower occupational self-efficacy beliefs compared with individuals with higheradaptability profiles.

Third, we wanted to extend Study 1 by investigating the extent to which the observed adaptability profiles are related to theoretical antecedents. This extension allowed us to explore more closely the potential causes behind the different profiles observed in Study 1. As an antecedent of the career adaptability profiles, we examined adaptivity, the "personality trait of flexibility or willingness to change" (Savickas \& Porfeli, 2012, p. 662). Specifically, we examined adaptivity using the two constructs that were used in the study by Hirschi et al. (2015): CSE, the "basic, fundamental appraisal of one's worthiness, effectiveness, and capability as a person" (Judge, Erez, Bono, \& Thoresen, 2003, p. 304), and proactivity, the relatively stable disposition to effect environmental change by taking personal initiative in a broad range of activities and situations (Crant, 2000). Previous studies (Hirschi et al., 2015; Tolentino et al., 2014; Zacher, 2014) found that CSE and proactivity are both significantly and positively related to all four career adaptability dimensions. We therefore expected that individual differences in these two variables would significantly predict group membership in one of the career adaptability profiles.

Hypothesis 3: High levels of adaptivity in terms of (a) CSE and (b) proactivity will increase the probability that individuals will belong to a higher-adaptability profile rather than a lower-adaptability profile.

\section{Methods Study 2}

Participants and procedure. We used archival data from a study by Hirschi and colleagues (2015) that included 1,260 German university students from a wide range of study majors. Participants were recruited with a procedure similar to the one used to recruit the participants in Study 1. We checked for multivariate outliers using the Mahalanobis distance based on the four adaptability subscales and identified 34 cases $(p<.001)$ that were excluded from the subsequent data analyses, resulting in a final 
sample of $\mathrm{N}=1,226$ participants, $67 \%$ female with a mean age of $23.96(\mathrm{SD}=3.14)$ years.

Measures. The same adaptability scale and four adapting measures (career planning, career decisionmaking difficulties, career exploration, and occupational self-efficacy) that were described in Study 1 were used. Adaptivity was assessed using the 12-item German-language version of the CSE scale developed by Judge et al. (Judge, Erez, Bono, \& Thoresen, 2003; Stumpp, Muck, Hülsheger, Judge, \& Maier, 2010), and proactivity was assessed using the seven-item German-language personal initiative questionnaire developed by Frese, Fay, Hilburger, Leng, and Tag (1997). Cronbach's alpha, the means and standard deviations, and the correlations among the variables for the final sample used in this study are reported in Table 1.

\section{Results and Discussion: Study 2}

Confirmatory factor analysis with the CAAS items. The model with four intercorrelated latent adaptability factors showed a moderately acceptable fit $(\chi 2=1366.05, \quad d f=246, \quad p<.001, \quad \mathrm{CFI}=.87$, TLI $=.86, \quad$ RMSEA $=.06, \quad$ SRMR $=.05) . \quad$ The intercorrelations among the four adaptability factors were small but significant (all $\mathrm{r}<.18, p<.001$ ). The examination of the modification indices showed several highly correlated error terms for the items within each scale. Using a stepwise process, we released three error terms until an acceptable model fit was reached $(\chi 2=992.52, d f=243, p<.001$, $\mathrm{CFI}=.92, \mathrm{TLI}=.91, \mathrm{RMSEA}=.05, \mathrm{SRMR}=.05$ ) .

Latent profile analysis. Based the same statistical procedure described for Study 1, we assessed two- to six-profile solutions and chose the five-profile solution because it had the lowest SABIC (7718.21) and a significant BLRT $(40.23, p<.05)$. The posterior classification probabilities and profile sizes were also adequate for this solution. The means of the subscales concern, control, curiosity, and confidence for the five profiles can be retrieved from Table 2 . Figure 1 shows the five latent profiles' standardized means for the four adaptability subscales. The first profile (2\%) was characterized by the lowest values for all four adaptability subscales and was named very low adaptability. The second profile (10\%) was also characterized by low adaptability subscale scoresalthough the scores were somewhat higher than those of the very low adaptability group-and was labeled low adaptability. The third latent profile (29\%) showed values slightly below the mean score for all four adaptability subscales and was named below average adaptability. The fourth profile (15\%) showed the highest values for all four adaptability subscales and was labeled high adaptability. The fifth (45\%) and most common profile was characterized by values slightly above the mean for all four adaptability subscales and was named above-average adaptability. In support of Hypothesis 1, all five latent profiles were quantitatively different, indicating different degrees of relatively homogeneously low to high adaptability subscale scores. There was no profile that differed qualitatively from the others.

To address Hypothesis 2, we again conducted the same analyses that were described in Study 1 using the BCH command in MPlus. The results (Table 3 and Figure 1) confirmed the findings from Study 1 that showed that the five latent adaptability profiles did homogeneously vary in terms of career planning, career decision-making difficulties, career exploration, and occupational self-efficacy. The students with profiles characterized by generally higher levels of the four adaptability measures also showed higher levels of adapting (with relatively lower levels of career decision-making difficulties). The Wald tests comparing the means of the adapting variables across the five measures (Table 3) showed that the most marked differences exist between the very low and low adaptability profiles compared with the above average and high adaptability profiles. These findings fully supported Hypothesis 2 .

To investigate Hypothesis 3, we used the R3STEP command in MPlus (Asparouhov \& Muthén, 2014). The R3STEP command performs multinomial logistic regressions to determine whether an increase in an 
antecedent variable is related to a higher probability of a participant belonging to one profile rather than another. The results (Table 4 and Figure 2) showed that the participants with higher adaptivity (i.e., more positive CSE and higher proactivity) were typically found in the latent profiles with higher adaptability. The multinomial regression results (Table 4) showed that CSE and proactivity values could significantly predict the latent profile of an individual. The only exception was the assignment of individuals to the very low or low adaptability groups, which could not be significantly predicted by CSE. These findings support Hypothesis 3 and indicate that differences in adaptivity are important for explaining membership in adaptability profile groups.

\section{General Discussion}

The purpose of this paper was to investigate career adaptability using a person-centered approach. This approach takes into account that within a given population, several subpopulations might exist that show different combinations of career adaptability resources. By investigating how these groups differ in terms of the antecedents and outcomes of career adaptability, our investigation expands on the existing variable-centered research, which focuses on the average relationship between career adaptability and the related variables within a given population. This paper aimed to broaden the literature by studying adaptability profiles rather than separate adaptability variables and by simultaneously testing the links between antecedents, profiles, and consequences. Our paper also aimed to understand the conditions under which more or less optimal patterns of career adaptability occur.

Our results across two independent samples from the same population confirmed that among German university students, distinct adaptability profiles can be identified. The results of both studies showed that with the exception of the helpless-passive profile in Study 1, all of the profiles were characterized by variation in the levels of the four adaptability resources. In other words, groups of students differed according to whether they possessed generally lower or higher adaptability across the four adaptability resources. However, the profiles could not be clearly distinguished by specific qualitatively different combinations of the four adaptability scores within a group. Accordingly, our results suggest that level effects clearly dominate shape effects in latent career adaptivity profiles. While it can be argued that shape differences are essential if person-centered approaches are to provide substantive additional utility beyond person-centered analyses, the extent to which level or shape differences are meaningful strongly depends on their theoretical bases (Morin \& Marsh, 2015). In the case of career adaptability, we would argue that strong level effects are theoretically meaningful because concern, control, curiosity, and confidence are theoretically and empirically related components of the higher-order construct of career adaptability (Savickas, 2013; Savickas \& Porfeli, 2012). Our results suggest that shape differences in career adaptability are not strong and that researchers can rightfully examine career adaptability using a variable-centered approach. For such variable-centered analyses in career adaptivity research, the strong level effects observed in our studies have important implications. These effects suggest that researchers can estimate the general career adaptability level as a latent factor underlying the four adaptability resources and explore the extent to which the general adaptability level is related to predictors and outcomes. This approach represents an alternative to the total career adaptability score that is commonly used in many published studies (e.g., Zacher, 2014). While such a total score represents overall career adaptability (as an aggregate construct consisting of nonredundant dimensions), the latent factor score represents an individual's general adaptability level. Our studies suggest that both approaches are theoretically and empirically justified and that exploring these two alternative approaches to conceptualize a 
Table 4

Three-step Results for Antecedents of Adaptability Classes in Study 2

\begin{tabular}{|c|c|c|c|c|c|c|c|c|c|c|}
\hline Antecedent & $\begin{array}{l}\text { Very low } \\
\text { v. Low }\end{array}$ & $\begin{array}{l}\text { Very low } \\
\text { v. Below } \\
\text { average }\end{array}$ & $\begin{array}{l}\text { Very low } \\
\text { v. High }\end{array}$ & $\begin{array}{l}\text { Very low } \\
\text { v. Above } \\
\text { average }\end{array}$ & $\begin{array}{l}\text { Low v. } \\
\text { Below } \\
\text { average }\end{array}$ & $\begin{array}{l}\text { Low v. } \\
\text { High }\end{array}$ & $\begin{array}{l}\text { Low v. } \\
\text { Above } \\
\text { average }\end{array}$ & $\begin{array}{l}\text { Below } \\
\text { average v. } \\
\text { High }\end{array}$ & $\begin{array}{l}\text { Below } \\
\text { average v. } \\
\text { Above } \\
\text { average }\end{array}$ & $\begin{array}{l}\text { High v. } \\
\text { Above } \\
\text { average }\end{array}$ \\
\hline $\begin{array}{l}\text { Core self- } \\
\text { evaluations }\end{array}$ & 0.22 & $1.77^{*}$ & $6.12^{* * *}$ & $4.11^{* * *}$ & $1.55^{* * *}$ & $5.90^{* * *}$ & $3.89 * * *$ & $4.35^{* * *}$ & $2.34^{* * *}$ & $-2.81^{* * *}$ \\
\hline Proactivity & $1.92 *$ & $3.36^{* * *}$ & $9.24^{* * *}$ & $6.20^{* * *}$ & $1.43^{* * *}$ & $7.31^{* * *}$ & $4.27^{* * *}$ & $5.88^{* * *}$ & $2.84^{* * *}$ & $-3.04^{* * *}$ \\
\hline
\end{tabular}

Note. $N=350$. Values are estimates for the R3STEP logistic regression analyses. Positive values indicate that higher values on the antecedent make a person more likely to be in the second latent profile out of the two being compared; negative values indicate that higher values on the antecedent make a person more likely to be in the first latent profile. Very low = Very low adaptability, Low = Low adaptability, Below average $=$ Below average adaptability, High = High adaptability, Above average = Above average adaptability.

${ }^{*} p<.05,{ }^{* *} p<.01,{ }^{* * *} p<.001$. 


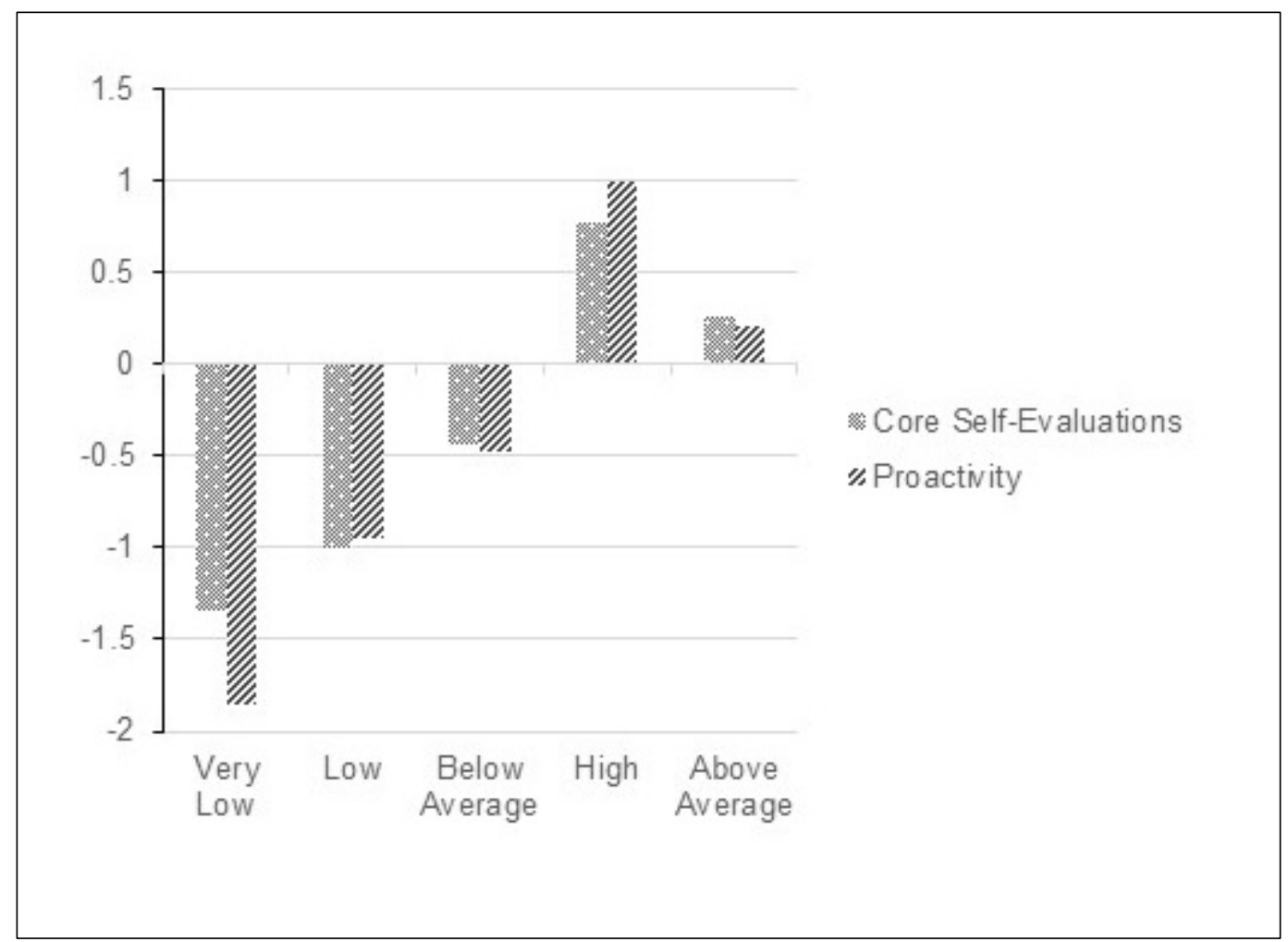

Figure 2. Standardized means of adaptivity (core self-evaluations and proactivity) by latent Adaptability profile in Study 2.

higher-order construct of career adaptability might provide useful insights.

Our results further provided support for the validity of the different adaptability profiles by showing significant differences in the level of adapting (career planning, career decision-making difficulties, career exploration, and occupational selfefficacy beliefs) across adaptability profiles. As expected, the students with a profile indicative of high adaptability resources showed significantly higher adapting attitudes and behaviors than did students with a low-adaptability profile. This finding advances previous results (Hirschi et al., 2015; Urbanaviciute et al., 2014) that showed positive correlations between specific dimensions of adaptability and aspects of adapting. The results of this paper show that not only are different adaptability resources related to better adapting on average but that students with generally low- or high-adaptability profiles differ in the degree to which they are capable of addressing career development tasks. Future studies could investigate the extent to which individuals with distinct adaptability profiles differ in other indicators of adapting (e.g., networking behaviors and training participation).

Finally, our investigation into the relation between adaptivity (CSE, proactivity) and adaptability profiles aimed to shed light on the potential reasons behind the different profiles. Hirschi et al. (2015) showed that adaptability was significantly correlated with adaptivity but that adaptability possessed incremental validity for predicting adapting beyond the effects of adaptivity. Extending these findings, the results of the present paper show that students with different adaptability profiles significantly differ in their adaptivity. This finding suggests that one important reason why different groups of students show distinct adaptability profile levels is because of significant differences in adaptivity across groups of students. Future research could explore in more detail 
the mediating mechanisms leading from adaptivity to the development of adaptability. Additionally, investigations of the moderators or the conditions under which adaptivity leads to higher adaptability would be important in this regard.

\section{Limitations}

One limitation of our studies is that both relied on same source cross-sectional data. This can induce a shared-method bias that might affect the observed relationships among the variables. For example, the fact that we observed strong level effects in the latent profiles could partially be explained by sharedmethod bias. However, because strong level effects make theoretical sense, it is unlikely that method bias was the main driver of the observed profile levels. Future studies could try to separate the assessment of profiles, antecedents, and outcomes by time and/or source to avoid this limitation. There are also statistical approaches for disentangling level effects from profile effects, which might lead to a clearer focus on the shape differences among the profiles. However, these approaches are not without limitations (e.g., they could decrease classification accuracy), and they need to be theoretically justified (Morin \& Marsh, 2015). Because we concluded that strong level effects are theoretically meaningful, we did not engage in such an examination.

\section{Implications for Practice}

Apart from increasing the theoretical understanding of the nature of career adaptability, our results also offer some implications for career counseling practice. The fact that we could identify distinct groups of students according to their adaptability profiles suggests that career counselors could identify groups of students with generally low adaptability profiles who might be in special need of support. Our results imply that if a student is low in a specific form of adaptability, it is likely that he or she is also low in other adaptability resources. This association means that if a career counselor encounters a client who shows a low level in a particular career adaptability resource (e.g., shows no concern for his or her vocational future), the counselor could justifiably suspect that this client is also likely to show low adaptability resources in other areas (e.g., a lack of curiosity) and might belong to a group of students with generally low adaptability. As our results further show, these students are more likely to exhibit lower levels of adapting responses and lower levels of basic adaptivity. Career counselors could attempt to identify these groups using standardized assessments (Savickas \& Porfeli, 2012) and then offer interventions that aim to increase their adaptability (Koen, Klehe, \& Van Vianen, 2012) or directly facilitate their adaptive attitudes and behaviors, for example, by helping them overcome career decision-making difficulties (Sampson, Lenz, Reardon, \& Peterson, 1999).

\section{References}

Abele, A. E., \& Wiese, B. S. (2008). The nomological network of selfmanagement strategies and career success. Journal of Occupational and Organizational Psychology, 81(4), 733-749. doi: 10.1348/096317907X256726

Asparouhov, T., \& Muthén, B. (2014). Auxiliary variables in mixture modeling: Three-step approaches using Mplus. Structural Equation Modeling, 21(3), 329-341. doi: 10.1080/10705511.2014.915181

Bakk, Z., \& Vermunt, J. K. (in press). Robustness of stepwise latent class modeling with continuous distal outcomes. Structural Equation Modeling.

Crant, J. M. (2000). Proactive behavior in organizations. Journal of Management, 26(3), 435-462. doi: 10.1016/S01492063(00)00044-1

Frese, M., Fay, D., Hilburger, T., Leng, K., \& Tag, A. (1997). The concept of personal initiative: Operationalization, reliability and validity in two German samples. Journal of Occupational and Organizational Psychology, 70(2), 139-161. doi: 10.1111/j.2044-8325.1997.tb00639.x

Gould, S. (1979). Characteristics of career planners in upwardly mobile occupations. Academy of Management Journal, 22(3), 539-550. doi: $10.2307 / 255743$

Guan, Y. J., Deng, H., Sun, J. Q., Wang, Y. N., Cai, Z. J., Ye, L. H., . . L Li, Y. H. (2013). Career adaptability, job search self-efficacy and outcomes: A three-wave investigation among Chinese university graduates. Journal of Vocational Behavior, 83(3), 561-570. doi: 10.1016/J.Jvb.2013.09.003

Hirschi, A. (2009). Career adaptability development in adolescence: Multiple predictors and effect on sense of power and life 
satisfaction. Journal of Vocational Behavior, 74(2), 145-155. doi: 10.1016/J.Jvb.2009.01.002

Hirschi, A., \& Herrmann, A. (2013). Assessing difficulties in career decision making among Swiss adolescents with the German My Vocational Situation Scale. Swiss Journal of Psychology, 72(1), 33-42. doi: 10.1024/1421-0185/a000097

Hirschi, A., Herrmann, A., \& Keller, A. C. (2015). Career adaptivity, adaptability, and adapting: A conceptual and empirical investigation. Journal of Vocational Behavior, 87, 1-10. doi: 10.1016/j.jvb.2014.11.008

Holland, J. L., Daiger, D. C., \& Power, P. G. (1980). My vocational situation. Palo Alto, CA: Consulting Psychologists Press.

Hu, L. T., \& Bentler, P. M. (1999). Cutoff criteria for fit Indexes in covariance structure analysis: Conventional criteria versus new alternatives. Structural Equation Modeling, 6(1), 1-55. doi: 10.1080/10705519909540118

Johnston, C. S., Luciano, E. C., Maggiori, C., Ruch, W., \& Rossier, J. (2013). Validation of the German version of the Career AdaptAbilities Scale and its relation to orientations to happiness and work stress. Journal of Vocational Behavior, 83(3), 295-304. doi: 10.1016/j.jvb.2013.06.002

Jörin, S., Stoll, F., Bergmann, C., \& Eder, F. (2003). EXPLORIX-das Werkzeug zur Berufswahl und Laufbahnplanung. Deutschsprachige Adaption und Weiterentwicklung des SelfDirected Search (SDS) nach John Holland. Test-Set Ausgabe Österreich, Verlag Hans Huber.

Judge, T. A., Erez, A., Bono, J. E., \& Thoresen, C. J. (2003). The core self-evaluations scale: Development of a measure. Personnel Psychology, 56(2), 303-331. doi: 10.1111/J.17446570.2003.Tb00152.X

Koen, J., Klehe, U.-C., \& Van Vianen, A. E. M. (2012). Training career adaptability to facilitate a successful school-to-work transition. Journal of Vocational Behavior, 81(3), 395-408. doi: 10.1016/j.jvb.2012.10.003

Marsh, H. W., Muthén, B., Asparouhov, T., Ludtke, O., Robitzsch, A., Morin, A. J. S., \& Trautwein, U. (2009). Exploratory Structural Equation Modeling, Integrating CFA and EFA: Application to Students' Evaluations of University Teaching. Structural Equation Modeling, 16(3), 439-476.

Morin, A. J. S., \& Marsh, H. W. (2015). Disentangling shape from level effects in person-centered analyses: An illustration based on university teachers' multidimensional profiles of effectiveness. Structural Equation Modeling 22(1), 39-59. doi: 10.1080/10705511.2014.919825

Muthén, L. K., \& Muthén, B. O. (2012). Mplus user's guide (7th ed.). Los Angeles, CA: Muthén \& Muthén.

Porfeli, E. J., \& Savickas, M. L. (2012). Career Adapt-Abilities ScaleUSA Form: Psychometric properties and relation to vocational identity. Journal of Vocational Behavior, 80(3), 748-753. doi: 10.1016/j.jvb.2012.01.009

Rigotti, T., Schyns, B., \& Mohr, G. (2008). A short version of the occupational self-efficacy scale: Structural and construct validity across five countries. Journal of Career Assessment, 16(2), 238-255. doi: 10.1177/1069072707305763

Rossier, J., Zecca, G., Stauffer, S. D., Maggiori, C., \& Dauwalder, J.-P. (2012). Career Adapt-Abilities Scale in a French-speaking Swiss sample: Psychometric properties and relationships to personality and work engagement. Journal of Vocational Behavior, 80(3), 734-743. doi: 10.1016/j.jvb.2012.01.004

Sampson, J. P., Lenz, J. G., Reardon, R. C., \& Peterson, G. W. (1999). A cognitive information processing approach to employment problem solving and decision making. Career Development Quarterly, 48, 3-18.

Savickas, M. L. (1984). Career maturity: The construct and its measurement. Vocational Guidance Quarterly, 32, 222-231.

Savickas, M. L. (1997). Career adaptability: An integrative construct for life-span, life-space theory. Career Development Quarterly, 45, 247-259. doi: 10.1002/j.2161-0045.1997.tb00469.x

Savickas, M. L. (2013). Career Construction theory and practice. In S. D. Brown \& R. W. Lent (Eds.), Career development and counseling: Putting theory and research to work (2nd ed., pp. 4270). Hoboken, NJ: Wiley.

Savickas, M. L., \& Porfeli, E. J. (2012). Career Adapt-Abilities Scale: Construction, reliability, and measurement equivalence across 13 countries. Journal of Vocational Behavior, 80(3), 661-673. doi: 10.1016/j.jvb.2012.01.011

Stumpp, T., Muck, P. M., Hülsheger, U. R., Judge, T. A., \& Maier, G. W. (2010). Core self-evaluations in Germany: Validation of a German measure and its relationships with career success. Applied Psychology, 59(4), 674-700. doi: 10.1111/J.14640597.2010.00422.X

Super, D. E. (1955). Dimensions and measurement of vocational maturity. Teachers College Record, 57, 152-163.

Super, D. E., \& Knasel, E. G. (1981). Career development in adulthood: Some theoretical problems and a possible solution. British Journal of Guidance and Counselling, 9, 194-201.

Tabachnik, B. G., \& Fidell, B. G. (2013). Using multivariate statistics. Boston, MA: Pearson

Tolentino, L. R., Garcia, P. R. J. M., Lu, V. N., Restubog, S. L. D., Bordia, P., \& Plewa, C. (2014). Career adaptation: The relation of adaptability to goal orientation, proactive personality, and career optimism. Journal of Vocational Behavior, 84(1), 39-48. doi: 10.1016/J.Jvb.2013.11.004

Urbanaviciute, I., Kairys, A., Pociute, B., \& Liniauskaite, A. (2014). Career adaptability in Lithuania: A test of psychometric properties and a theoretical model. Journal of Vocational Behavior, 85(3), 433-442. doi: 10.1016/j.jvb.2014.09.005

van Vianen, A. E. M., De Pater, I. E., \& Preenen, P. T. Y. (2009). Adaptable careers: Maximizing less and exploring more. The Career Development Quarterly, 57(4), 298-309. doi: 10.1002/j.2161-0045.2009.tb00115.x

Vondracek, F. W., \& Porfeli, E. (2002). Integrating person- and function-centered approaches in career development theory and research. Journal of Vocational Behavior, 61(3), 386-397. doi: 10.1006/jvbe.2002.1881 
Wang, M., \& Hanges, P. J. (2011). Latent Class Procedures: Applications to Organizational Research. Organizational Research Methods, 14(1), 24-31. doi: $10.1177 / 1094428110383988$

Zacher, H. (2014). Career adaptability predicts subjective career success above and beyond personality traits and core selfevaluations. Journal of Vocational Behavior, 84(1), 21-30. doi: 10.1016/J.Jvb.2013.10.002 